\title{
Experimental Organism Anal Sac Gland
}

National Cancer Institute

\section{Source}

National Cancer Institute. Experimental Organism Anal Sac Gland. NCI Thesaurus. Code C125895.

Apocrine gland of the anal sac. 